\title{
Consequences of Enamel Preparation with Sodium Hypochlorite, Polyacrylic and Phosphoric Acids for the Bonding of Brackets with Resin-modified Glass Ionomer Cements
}

\author{
Alessandra Marques Trindade ${ }^{\mathrm{a}}$,Tatiana Bahia Junqueira Pereira ${ }^{\mathrm{a}}$, Perrin Smith Neto ${ }^{\mathrm{a}}$,
} Martinho Campolina Rebello Horta ${ }^{\mathrm{a}}$,Matheus Melo Pithon ${ }^{\mathrm{b}}$, Emílio Akaki ${ }^{\mathrm{a}}$, Dauro Douglas Oliveira ${ }^{\mathrm{a} *}$

${ }^{a}$ Departament of Dentistry, Graduate Program in Orthodontics, Pontifical Catholic University of Minas Gerais - PUC Minas, Belo Horizonte, MG, Brazil ${ }^{\mathrm{b}}$ Departament of Health, Southwest Bahia State University - UESB, Jequié, BA, Brazil

Received: October 6, 2012; Revised: July 19, 2013

\begin{abstract}
The aim of this study was to evaluate the effects of deproteinization with $5.25 \%$ sodium hypochlorite $(\mathrm{NaOCl})$ prior to enamel conditioning with $10 \%$ polyacrylic acid (PAA) and $35 \%$ phosphoric acid (PA) on the bond strength (BS) of brackets bonded with resin-modified glass ionomer cement (RMGIC). One hundred human premolars extracted for orthodontic reasons were divided into 5 groups $(\mathrm{n}=20$ in each group): G1 (control), enamel conditioning with PA, application of adhesive and bonding of brackets with Transbond ${ }^{\mathrm{TM}}$ XT composite resin (3M/Unitek, Monrovia, CA, USA); G2, enamel conditioning with PAA and bonding with RMGIC (Fuji Ortho ${ }^{\mathrm{TM}}$ LC, GC America, Alsip, IL, USA); G3, NaOCltreated enamel, conditioning with PAA and bonding with RMGIC; G4, enamel conditioning with PA and bonding with RMGIC; and G5, NaOCl-treated enamel, conditioning with PA and bonding with RMGIC. Once the brackets were bonded, the teeth were stored in distilled water for 24 hours at room temperature and pressure until being subjected to shear stress in a Universal Mechanical Testing Machine (EMIC ${ }^{\circledast}$ DL 500, São José dos Pinhais, PR, Brazil). The BS value was higher in G1 $(17.08 \pm 6.39)$ than in any of the experimental groups $(p<0.05)$. No statistically significant differences were noted between groups using RMGIC $(p>0.05)$, except between G3 $(9.86 \pm 2.90)$ and G5 $(5.00 \pm 2.49)$. No statistically significant differences were noted between the mean Adhesive Remnant Index values among the evaluated groups $(\mathrm{p}>0.05)$. Conclusion: The use of $\mathrm{NaOCl}$ combined with PAA increased the BS of brackets bonded with RMGIC. The deproteinization of the group treated with PA reduced the shear bond strength of the brackets.
\end{abstract}

Keywords: bracket, dental enamel, glass ionomer cements

\section{Introduction}

The search for the ideal orthodontic bonding material persists, one that provides physical, chemical, mechanical and biological characteristics to more effectively meet the clinical needs of orthodontists. One of the main challenges lies in achieving a sufficient bond strength that supports both masticatory and orthodontic mechanical loads without being too strong to jeopardize the integrity of the enamel upon removal of the accessories. Furthermore, the ideal bonding system should provide adequate working time for the orthodontist to position the accessories correctly, and it should be biocompatible ${ }^{1}$.

The maintenance of adequate oral hygiene alongside the use of fixed braces remains a challenge for orthodontic patients and the development of white spot lesions during the orthodontic treatment is still a source of concern for dental professionals ${ }^{2,3}$. Bonding materials based on glass ionomer cement (GIC) have been commercially available for a long period of time $e^{4}$ and these materials possess many important properties, such as biocompatibility with the enamel and

*e-mail: dauro.bhe@gmail.com dentin, and cariostatic effect. However, conventional GIC-based products exhibit low bond strengths (BSs) for bonding orthodontic brackets ${ }^{5-7}$. Resin-modified glass ionomer cement (RMGIC) was developed with the purpose of increasing bond strength. This modification has improved the performance of this cement as an orthodontic bonding agent via the addition of resinous components. However, even this higher BS remains below the strengths that were recorded for composite resins ${ }^{8-10}$.

The use of $5.25 \%$ sodium hypochlorite $(\mathrm{NaOCl})$ as a enamel deproteinizing agent prior to acid conditioning and bracket bonding with RMGIC has been suggested as a means of increasing bond strength. The removal of organic matter and the acquired pellicle from the enamel would affect the quality of the conditioning performed ${ }^{11-13}$ and consequently increase the BS. However, the number of studies supporting these assumptions is limited and the type of acid (PA) used after deproteinization was not the one recommended by the RMGIC manufacturer.

Thus, this study aimed to evaluate the effects of enamel deproteinization with $5.25 \% \mathrm{NaOCl}$ on the bonding of 
brackets with RMGIC prior to conditioning with polyacrylic and phosphoric acids. Any differences in the BS of brackets bonded with RMGIC to enamels conditioned with polyacrylic acid (PAA) or phosphoric acid (PA) were also assessed.

\section{Material and Methods}

One hundred premolars from the Human Teeth Bank linked to the Department of Dentistry of the Pontifical Catholic University of Minas Gerais (Pontifícia Universidade Católica de Minas Gerais - PUC Minas) were acquired free of any soft tissue. The premolars were stored in distilled water at room temperature until they were ready for use. According to the inclusion criteria, all teeth had an intact vestibular surface and no carious lesions, cavitations or restorations. The PUC Minas Research Ethics Committee approved all experimental procedures described in this study.

A mounting device was built to standardize the preparation of the teeth and to ensure proper control during bonding (Figure 1). Each group had the vestibular surface of the teeth cleaned with a mixture of pumice (Asfer Indústria Química Ltda., São Caetano do Sul, SP, Brazil) and water with the help of a rubber cup that was operated at a low speed for 5 seconds. The teeth were randomly distributed into 5 different groups of enamel treatment $(n=20$ in each group). Following this step, 0.022 ' $\times 0.028^{\prime}$ ' Standard Edgewise metallic brackets (American Orthodontics, Sheboygan, WI, USA) were positioned to the centers of the clinical crowns, the excess of the bonding material was removed from the edges of the brackets and light curing was performed. The premolars were divided into the following groups:

G1 - control: enamel conditioned with 35\% PA for 30 seconds, rinsed with water for 10 seconds and dried with oil-free compressed air. A thin layer of adhesive was placed and polymerized for 10 seconds. The brackets were bonded with composite resin (Transbond ${ }^{\mathrm{TM}} \mathrm{XT}, 3 \mathrm{M} / \mathrm{Unitek}$, Monrovia, CA, USA).

G2 - enamel conditioned with $10 \%$ PAA for 20 seconds, rinsed with water for 10 seconds and dried with oil-free compressed air. The surface of the enamel was moistened with water, as recommended by the manufacturer and the

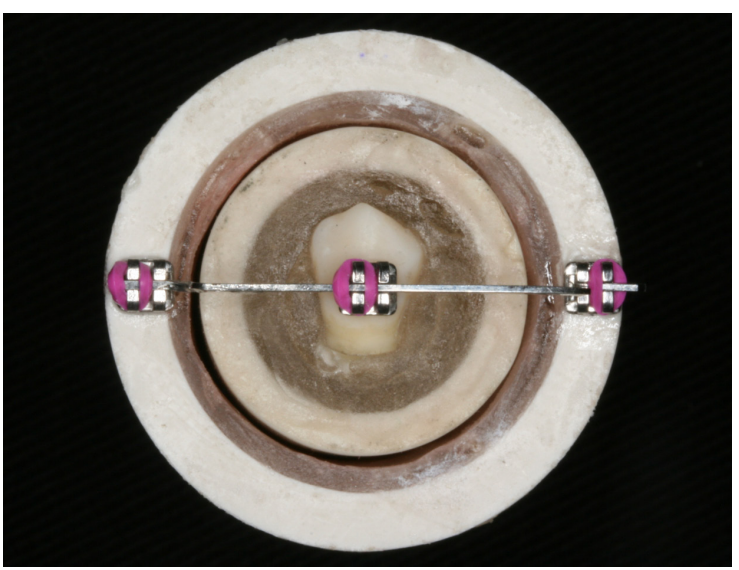

Figure 1. Premolar crown suspended in the tube during bonding. brackets were bonded with RMGIC (Fuji Ortho ${ }^{\mathrm{TM}}$ LC, GC America, Alsip, IL, USA).

G3 - enamel deproteinized with $5.25 \% \mathrm{NaOCl}$ for 60 seconds, rinsed with water, air-dried, conditioned with $10 \%$ PAA for 20 seconds, rinsed with water for 10 seconds and dried with oil-free compressed air. The surface of the enamel was moistened with water and the brackets were bonded with RMGIC.

G4 - enamel conditioned with 35\% PA for 30 seconds, rinsed with water for 10 seconds and dried with oil-free compressed air. The brackets were bonded with RMGIC.

G5: enamel deproteinized with $5.25 \% \mathrm{NaOCl}$ for 60 seconds, rinsed with water, air-dried, conditioned with $35 \%$ PA for 30 seconds, rinsed with water for 10 seconds and dried with oil-free compressed air and the brackets were bonded with RMGIC.

The same operator performed all procedures as per the recommendations of the manufacturers. The polymerization of the bonding material was performed with a photopolymerizer (Hilux ${ }^{\mathrm{TM}} 250$ Halogen, Benlioglu, Ankara, Turkey) for 10 seconds on the mesial, distal, cervical and occlusal surfaces of the brackets.

Once the brackets were bonded, the teeth were stored in distilled water for 24 hours at room temperature, after which they were tested for shear strength. A Universal Mechanical Testing Machine (EMIC ${ }^{\circledR}$ DL 500, São José dos Pinhais, Paraná, PR, Brazil) was used with a 500-Newton load cell at an operating speed of $0.5 \mathrm{~mm}$ per minute. The chisel-type tip was attached to the upper portion of the machine and was positioned to evenly contact the bases of the brackets. The values were obtained in Newtons $(\mathrm{N})$ and transformed to megapascals (MPa) using the projection of the area at the base of the bracket $\left(10.55 \mathrm{~mm}^{2}\right)$, as informed by the manufacturer. This study was conducted at the Laboratory of Structural Analysis of the Department of Mechanical Engineering at PUC Minas.

AUSB Digital Microscope (Digivision, Dongguan, Guangdong, China) was used to microscopically photograph the vestibular surfaces of the premolars after debonding of the brackets, at 20X magnification. An examiner analyzed the obtained images, after which the percentage of adhesive remaining on the enamel was scored using the Adhesive Remnant Index (ARI) ranging from 0 to 3, as reported by Artun and Bergland ${ }^{14}$ :

0: No adhesive left on the surface of the enamel.

1: Less than $50 \%$ of the adhesive remained on the tooth.

2: More than $50 \%$ of the adhesive remained on the tooth.

3: All of the adhesive remained on the tooth.

Following the debonding of the brackets and the analysis of bonding failure, the enamel surface and remaining adhesive of one tooth from each group were microscopically photographed with a scanning electron microscope (SEM) (Shimadzu SSX-550, Shimadzu do Brasil, São Paulo, SP, Brazil). The randomly selected teeth were subsequently prepared for observation under 500X magnification.

The shear bond strength variable was cardinal in nature and had a normal distribution (normality was assessed using the D'Agostino-Pearson test). The presence of differences in BS between the groups was evaluated by one-way analysis of variance (ANOVA), followed by the Bonferroni post hoc test. 
The ARI variable was ordinal in nature. Therefore, the Kruskal-Wallis test followed by Dunn's post hoc test was applied to assess any differences in the ARI values between the groups. Statistical tests were performed using GraphPad Prism software (GraphPad Software, San Diego, CA, USA).

\section{Results}

The mean value for the shear BS in the control group was significantly higher $(\mathrm{p}<0.05)$ than the values obtained for all other experimental groups. The mean BS was lower in $\mathrm{G} 2(8.60 \pm 5.29)$ than in G3 $(9.86 \pm 2.90)$, although this difference was not significant $(\mathrm{p}>0.05)$. The groups treated with phosphoric acid (G4 and G5) exhibited lower mean BS values than did G2, although no significant differences were identified $(\mathrm{p}>0.05)$. The mean $\mathrm{BS}$ was higher in G3 $(9.86 \pm 2.90)$ than in G4, although not significantly ( $p>0.05)$. The mean BS was statistically lower in G5 $(p<0.05)$ than in G3. The mean values and standard deviations for the shear BS in all groups are shown in Table 1 and Figure 2.

Regarding the ARI values (Table 2), G3, G4 and G5 showed a tendency for all of the adhesive to remain on the enamel after bracket debonding, similar to that observed in the control group. However, the results obtained for G2 were different from those for the other groups, with less than $50 \%$ of the adhesive remaining on the enamel. Despite these tendencies, the Kruskal-Wallis test revealed no significant

Table 1. Means and standard deviations of measured bond strengths in the 5 groups.

\begin{tabular}{ccl}
\hline Group & Shear Bond Strength (MPa) & \multicolumn{1}{c}{ p value* } \\
\hline G1 & $17.08 \pm 6.39$ & $\begin{array}{l}\text { versus } \mathrm{G} 2 / \mathrm{p}<0.05 \\
\text { versus } \mathrm{G} 3 / \mathrm{p}<0.05 \\
\text { versus } \mathrm{G} 4 / \mathrm{p}<0.05 \\
\text { versus } \mathrm{G} 5 / \mathrm{p}<0.05\end{array}$ \\
\hline G2 & $8.60 \pm 5.29$ & $\begin{array}{l}\text { versus } \mathrm{G} 3 / \mathrm{n} . \mathrm{s} . \\
\text { versus } \mathrm{G} 4 / \mathrm{n} . \mathrm{s} . \\
\text { versus } \mathrm{G} 5 / \mathrm{n} . \mathrm{s} .\end{array}$ \\
\hline G3 & $9.86 \pm 2.90$ & $\begin{array}{l}\text { versus } \mathrm{G} 4 / \mathrm{n} . \mathrm{s} . \\
\text { versus } \mathrm{G} 5 / \mathrm{p}<0.05\end{array}$ \\
\hline G4 & $6.72 \pm 2.31$ & versus $\mathrm{G} 5 / \mathrm{n} . \mathrm{s}$. \\
\hline $\mathrm{G} 5$ & $5.00 \pm 2.49$ & \\
\hline
\end{tabular}

*p value obtained from one-way ANOVA followed by the Bonferroni post hoc test; $\mathrm{n} . \mathrm{s} .=$ not significant $(\mathrm{p}>0.05)$.

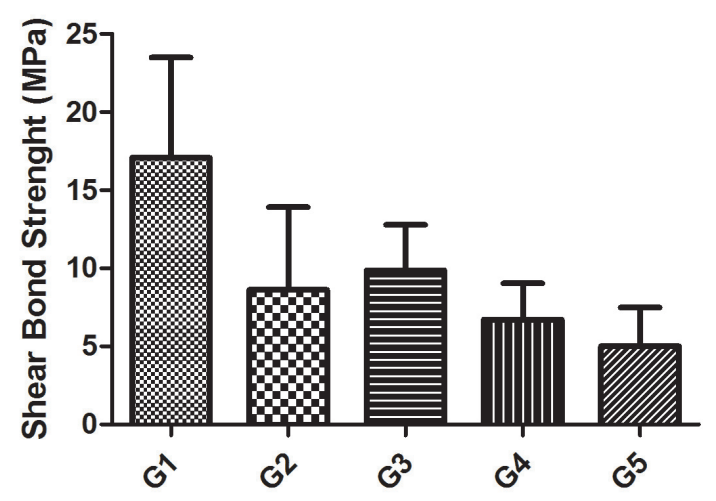

Figure 2. Means and standard deviations of shear bond strenght measured in the 5 groups under assessment. differences between the ARI values among the studied groups ( $p>0.05)$. Figure 3 illustrates the enamel surfaces and the adhesive remnants corresponding to a sample from each studied group.

\section{Discussion}

The mean values for the shear BS observed in groups G1, G2, G3 and G4 were higher than the minimum clinically acceptable values suggested by Reynolds ${ }^{15}$. In contrast, G5 had values below this range.

Espinosa et al. ${ }^{12}$ conducted a study that aimed to assess whether the retentive properties of enamel improved with the use of $5.25 \% \mathrm{NaOCl}$ as a step prior to acid conditioning (37\% PA). A larger number of type 1 and 2 decalcification patterns were observed, whereas a predominance of type 3 patterns was noted in the absence of $\mathrm{NaOCl}$. When assessing enamel micromorphology, Silverstone ${ }^{16}$ noted a higher degree of retention for type 1 and 2 decalcification patterns than for type 3 . The topographic quality of the conditioning cannot be clinically observed.

Espinosa et al. ${ }^{12}$ and Justus et al. ${ }^{17}$ were pioneers in evaluating whether enamel deproteinization with $\mathrm{NaOCl}$ prior to PA conditioning would increase the shear BS of brackets bonded with RMGIC. The BS of these brackets was compatible with that obtained with composite resin. The aforementioned authors did not assess the combination of $\mathrm{NaOCl}$ and PAA, which is the type of acid recommended by the RMGIC manufacturer.

Therefore, the present study aimed to assess whether deproteinization of the enamel prior to conditioning with different acids (10\% PAA and 35\% PA) would increase the BS in brackets bonded with RMGIC. An increase was noted in those groups conditioned with PAA when the enamel was treated with $\mathrm{NaOCl}$, though this difference was not statistically significant when compared with the other experimental groups. A key difference between the data obtained in this study and those presented by Justus et al. ${ }^{17}$ was that the increase in $\mathrm{BS}$ resulting from the use of $\mathrm{NaOCl}$ was statistically significant in the latter report.

A reduction in the BS was noted in the groups conditioned with PA when the enamel was first treated with $\mathrm{NaOCl}$. However, this difference was not statistically significant. This finding implies that when the enamel topography was analyzed after acid conditioning, no significant improvement was noted in the quality of the decalcification pattern in the deproteinized group compared with the non-deproteinized group. These data are in agreement with a study by Ahuja et al. ${ }^{18}$, which reported a reduction in the quality of the decalcification pattern of enamels deproteinized with $\mathrm{NaOCl}$ and conditioned with $\mathrm{PA}$

Table 2. Adhesive Remnant Index (ARI) scores for the evaluated groups.

\begin{tabular}{ccccc}
\hline \multicolumn{5}{c}{ ARI } \\
\hline Group & $\mathbf{0}$ & $\mathbf{1}$ & $\mathbf{2}$ & $\mathbf{3}$ \\
\hline $\mathbf{1}$ & 0 & 4 & 5 & 11 \\
$\mathbf{2}$ & 3 & 6 & 5 & 6 \\
$\mathbf{3}$ & 0 & 5 & 6 & 9 \\
$\mathbf{4}$ & 0 & 3 & 7 & 10 \\
$\mathbf{5}$ & 0 & 3 & 4 & 13 \\
\hline
\end{tabular}



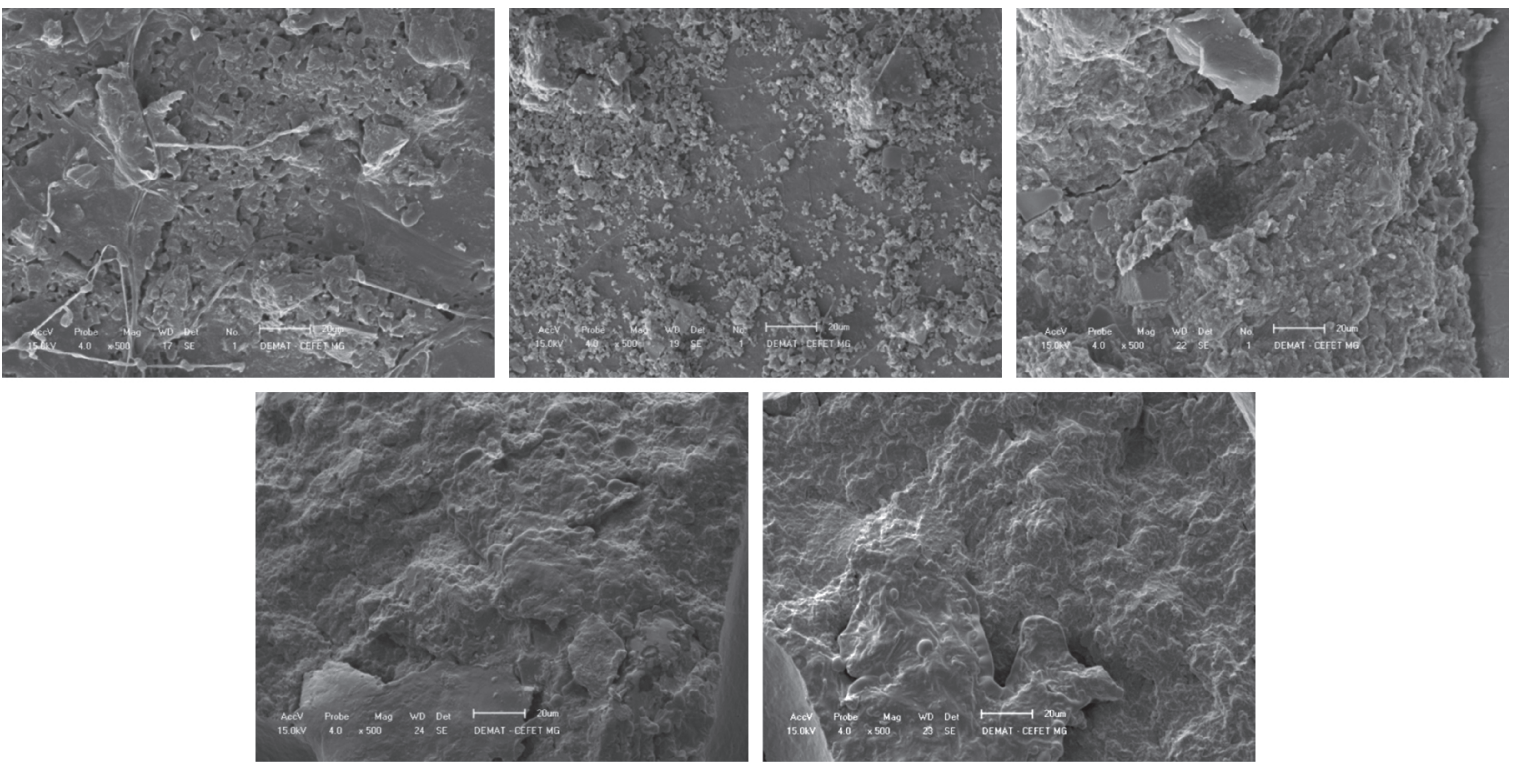

Figure 3. Microscopic images of the enamel surfaces after debonding of the brackets and their remaining adhesive. A - group G1; B - group G2; C - group G3; D - group G4; and E - group G5.

(53.58\%, types 1 and 2). Pattern types 1 and 2 were found in $55.76 \%$ of the enamel surfaces in the group that did not receive $\mathrm{NaOCl}$. Similar to the present study, Ahuja et al. ${ }^{18}$ found no significant differences between the studied groups. However, the aforementioned results are not in agreement with the findings of Justus et al. ${ }^{17}$, who reported a statistically significant increase in $\mathrm{BS}$ when $\mathrm{NaOCl}$ was used prior to conditioning with PA.

Although the manufacturer recommends PAA, Bishara, Fehr and Jakobsen ${ }^{19}$ and Toledano et al. ${ }^{20}$ reported that the BS of RMGIC is only clinically acceptable when the enamel is conditioned with PA. Reduced BS was noted when the enamel was treated with $10 \%$ or $20 \%$ PAA. Pithon et al. ${ }^{3}$ also reported that brackets bonded with RMGIC and previously conditioned with PA might display satisfactory values of shear BS, similar to those observed for brackets bonded with composite resin. The authors of the present study considered testing and comparing the BS of brackets conditioned with PAA and PA as one of the study goals.

Bishara et al. ${ }^{21}$ reported results similar to those of this study. These researchers concluded that the group of brackets bonded with RMGIC and previously treated with PAA showed greater shear BS compared with the group with enamel treated with PA. Horiuchi et al. ${ }^{4}$ microscopically observed enamel surfaces after acid conditioning using different agents (including PAA and PA) and subsequently conducted tests of shear strength on brackets bonded with composite resin. Surfaces conditioned with PAA remained virtually intact, whereas those conditioned with PA acid were porous. In contrast, the samples conditioned with PAA had greater BSs compared with those treated with PA. These values agree with those from this study. Despite the addition of resinous components to the liquid of conventional GIC, RMGIC maintained some of the good properties of conventional glass ionomer cements and also gained several advantages, including improved working time and initial mechanical properties. However, the final resistance of RMGIC is not greater than that of conventional GIC ${ }^{21,22}$.
Polyacrylic acid has been used to condition surfaces that subsequently receive conventional GIC or RMGIC. Unlike phosphoric acid, PAA is composed of large molecules and minimally penetrates the dental enamel only promoting cleaning of the surface. After the enamel is treated with PAA, the bonded RMGIC displays no extensions (tags) into the enamel structure. Therefore, RMGIC bonding has been shown to be more chemically activated than mechanically activated $^{23}$. Considering the aforementioned fact and the findings obtained in this study, it can be concluded that the size of the acid molecules may not significantly influence the retention of the RMGIC.

No significant differences were noted in the ARI values between the evaluated groups. These data contradict the findings from Justus et al. ${ }^{17}$, which showed that the cement predominantly remained on the enamel in groups of teeth treated with $\mathrm{NaOCl}$ prior to acid etching.

Enamel deproteinization using $\mathrm{NaOCl}$ as a complement to acid conditioning to enhance $\mathrm{BS}$ is an innovative technique rarely reported in the literature that should be better tested in terms of both clinical and laboratory aspects. Even with the help of $\mathrm{NaOCl}$, acid conditioning with polyacrylic and phosphoric acids was insufficient to obtain shear BS values similar to those obtained with composite resins.

\section{Conclusions}

This study allows us to draw the following conclusions:

- Enamel deproteinization with $\mathrm{NaOCl}$ prior to conditioning with polyacrylic and phosphoric acid not promote significant improvements in strength of brackets bonded with RMGIC;

- No differences were noted between the BS values of brackets bonded with RMGIC on enamels conditioned solely with polyacrylic or phosphoric acid;

- No differences were noted between the amounts of adhesive remaining in each group after debonding of the brackets bonded with RMGIC. 


\section{References}

1. Buonocore MG. A simple method of increasing the adhesion of acrylic filling material to enamel surface. Journal of Dental Research. 1955; 34:849-853. PMid:13271655. http://dx.doi.or $\mathrm{g} / 10.1177 / 00220345550340060801$

2. Ianni D F ${ }^{\circ}$, Silva TBC, Simplício AHM, Lofredo LCM and Ribeiro RP. Avaliação in vitro da força de adesão de materiais de colagem em Ortodontia: Ensaios mecânicos de cisalhamento. Revista Dental Press de Ortodontia e Ortopedia Facial. 2004; 9:39-48.

3. Pithon MM, Dos Santos RL, DE Oliveira MV, Ruellas AC and Romano FL. Metallic brackets bonded with resin-reforced glass ionomer cements under different enamel conditions. Angle Orthodontistontist. 2006; 76:700-704. PMid:16808580.

4. Horiuchi S, Kuroda S, Hiasa M, Suge T, Saku S, Hamada K et al. Reinforcement of bond strength of self-etching orthodontic adhesive. Angle Orthodontistontistontist. 2011; 0:1-5.

5. Wilson AD and Kent BE. A new translucent cement for dentistry. The glass ionomer cement. British Dental Journal. 1972; 132:133-135. PMid:4501690. http://dx.doi. org/10.1038/sj.bdj.4802810

6. Forsten L. Fluoride release and uptake by glassionomers and related materials and its clinical effect. Biomaterials. 1998; 19:503-508. http://dx.doi.org/10.1016/ S0142-9612(97)00130-0

7. Newman RA, Newman GV and Sengupta A. In vitro bond strengths of resin modified glass ionomer cements and composite resin self-cure adhesives: introduction of an adhesive system with increased bond strength and inhibition of decalcification. Angle Orthodontistontist. 2001; 71:312-317. PMid:11510641.

8. Bishara SE, Ostby AW, Laffon J and Warren JJ. A selfconditioner for resin modified glass ionomers in bonding orthodontic brackets. Angle Orthodontistontist. 2007; 77:711715. PMid:17605493. http://dx.doi.org/10.2319/070606-280.1

9. Choo SC, Ireland AJ and Sherriff M. An in vivo investigation into the use of resin-modified glass poly (alkenote) cements as orthodontic bonding agents. European Journal of Orthodontics. 2001; 23:403-449. http://dx.doi.org/10.1093/ ejo/23.4.403

10. Ewoldensen $\mathrm{N}$ and Demke RS. A review of orthodontic cements and adhesives. American Journal of Orthodontics and Dentofacial Orthopedics. 2001; 120:45-48. PMid:11455376. http://dx.doi.org/10.1067/mod.2001.117207

11. Wheeler AW, Foley TF and Mamandras A. Comparison of fluoride release protocols for in-vitro testing of 3 orthodontic adhesives. American Journal of Orthodontics and Dentofacial Orthopedics. 2002; 121:301-309. http://dx.doi.org/10.1067/ $\bmod .2002 .120160$
12. Espinosa R, Valencia R, Uribe M, Ceja I and Saadia M. Emanel desproteinization and its effect on acid etching: an in vitro study. Journal of Clinical Pediatric Dentistry. 2008; 33:13-20. PMid:19093646.

13. Espinosa R, Valencia R, Uribe M, Ceja I and Saadia M. Resin replica in enamel deproteinization and its effect on acid etching. Journal of Clinical Pediatric Dentistry. 2010; 35:47-52. PMid:21189764.

14. Artun J and Bergland S. Clinical trials with crystal growth conditioning as na alternative to acid-etch enamel pretreatment. American Journal of Orthodontics and Dentofacial Orthopedics. 1984; 85:333-340.

15. Reynolds IR. A review of direct orthodontic bonding. British Journal of Orthodontics. 1975; 2:171-178.

16. Silverstone LM, Saxton CA, Dogon IL and Fejerskov. Variation in the pattern of acid etching of human dental enamel examined byscanning electron microscopy. Caries Research. 1975; 9:373-387. PMid:1055640. http://dx.doi. org/10.1159/000260179

17. Justus R, Cubero T, Ondarza R and Morales F. A new technique with sodium hypochorite to increase bracket shear bond strength two adhesive systems with enamel surface deproteinization before etching. Seminars in Orthodontics. 2010; 16:66-75. http://dx.doi.org/10.1053/j.sodo.2009.12.006

18. Ahuja B, Yeluri R, Baliga MS and Munshi AK. Enamel deproteinization before acid etching - A scanning electron microscopic observation. Journal of Clinical Pediatric Dentistry. 2010; 35:169-172. PMid:21417119.

19. Bishara SE, Ferh DE and Jakobsen JR. A comparative study of the debonding strengths of different ceramic brackets, enamel conditioners, and adhesives. American Journal of Orthodontics and Dentofacial Orthopedics. 1993; 104:170-179. http://dx.doi. org/10.1016/S0889-5406(05)81007-8

20. Toledano M, Osorio R, Osorio E, Romeo A, Higuera B and García-Godoy E. Bond strength of orthodontic brackets using different light and self-curing cements. Angle Orthodontistontist. 2003; 73:56-63. PMid:12607856.

21. Bishara SE, Soliman M, Laffoon JF and Warren J. Shear bond strength of a new high fluoride release glass ionomer adhesive. Angle Orthodontistontist. 2008; 78:125-128. PMid:18193962. http://dx.doi.org/10.2319/100405-347.1

22. Smith DC and Cartz L. Crystalline interface formed by polyacrilic acid and tooth enamel. Journal of Dental Research. 1973; 52:1155. PMid:4517760. http://dx.doi.org/10.1177/002 20345730520053201

23. Fjeld M and Øgaard B. Scanning electron microscopic evaluation of enamel surfaces exposed to 3 orthodontic bonding systems. American Journal of Orthodontics and Dentofacial Orthopedics. 2006; 130:575-581. PMid:17110254. http:// dx.doi.org/10.1016/j.ajodo.2006.07.002 